\title{
A DisCIPLINA LÍNGUA E LITERATURA INGLESA: primórdios e desdobramentos
}

\author{
Solange Ribeiro de Oliveira \\ UFMG
}

\begin{abstract}
Naquele tempo, quando ainda não existia uma Faculdade de Letras, unidade universitária independente, mas apenas um Departamento de Letras da Faculdade de Filosofia da UMG, o estudo da língua e das literaturas de expressão inglesa, hoje desdobrado em inúmeras disciplinas, limitava-se a duas, Lingua e Literatura Inglesa e Literatura Norte-Americana. Por outro lado, não havendo ainda os colegiados de Graduação e Pós-Graduação, as disciplinas e seu conteúdo obedeciam simplesmente à formulação de seus fundadores, os antigos catedráticos.

Ao olhar de hoje, pareceriam seres esdrúxulos. Os mais antigos nem sequer deviam a cátedra à aprovação em concurso, mas a nomeações federais, com eventuais motivações políticas. Não que, aos nomeados, faltasse mérito. Dada a inexistência de instituições específicas, faltava-lhes, sim, formação superior formal em Letras. Por outro lado, sobravam entre eles os bacharéis em direito (como Mário Casasanta e Abgar Renault, de Língua Portuguesa e Inglesa, respectivamente) ou egressos de antigos seminários, como José Lourenço de Oliveira, de Latim.

Em função de seu auto-didatismo em Letras e da ausência de especialização, os catedráticos tinham as qualidades de seus defeitos: visão pessoal, interesse por outras áreas (parente da atual interdisciplinaridade) e singular independência. O preço a pagar eram os defeitos dessas qualidades. $\mathrm{O}$ autodidatismo implicava certo isolacionismo. Contatos acadêmicos só eram frequentes em poucos círculos, como a Universidade de São Paulo, monstro sagrado da época, aureolado pela herança lendária de nomes como Lévy-Strauss.

Aos velhos catedráticos atribuíam-se comportamentos idiossincráticos, beirando, no limite, à arbitrariedade. A título de exemplo, vá lá um caso extremo: o detentor de uma cátedra (este, já concursado) arrogava-se o direito de confiar a quem quisesse a avaliação de trabalhos acadêmicos - no caso, à esposa, que não tinha qualquer vínculo com a universidade. A bem da verdade, ocasionais atos exóticos não passavam de efeitos colaterais de algo muito bom, uma grande liberdade. Ela permitia ao catedrático indicar, sem concurso, os professores assistentes. Mas também garantia, constitucionalmente, a livre expressão do pensamento, apoiada na autonomia e vitaliciedade da cátedra. Aliadas às exigências da estruturação departamental, que só veio com a reforma universitária, essa autonomia e vitaliciedade da cátedra - inconvenientes para os detentores do poder - contribuíram para sua extinção, o que possibilitou o afastamento sumário de vários docentes, nos anos negros do AI-5.
\end{abstract}


Evidentemente, os traços atribuídos genericamente à figura do catedrático não coincidiam com perfis individuais. A responsável pela cátedra de Literatura NorteAmericana, Alita Sodré, excepcionalmente jovem para a função, não poderia ser mais discreta e disciplinada em seu desempenho. Entre seus méritos, contava-se o de exigir a leitura de textos em inglês, em vez das tradicionais traduções. Extremamente dedicada, recebia os estudantes em sua casa, em animadas aulas complementares. Nosso outro catedrático foi Abgar Renault, fundador da disciplina Língua e Literatura Inglesa. Alto, esguio, sempre impecavelmente vestido, usando um indefectível chapéu (já então fora de moda), tinha a fala clara, seca e incisiva, congruente com sua fama de severidade. A grande queixa contra ele é que só iniciava a aula a partir das 11 horas. Vendo distante o almoço, os mais vorazes se preveniam com discretos sanduíches. Entretanto, diante de um estudante aplicado, ou de um trabalho mais bem alinhavado, aquela secura toda se derretia. Atencioso, Abgar nos telefonava para simples conversas, ou para anunciar eventuais ausências, em missões junto a órgãos internacionais como a UNESCO, ou como Secretário e Ministro de Educação.

A educação sempre foi seu grande interesse. Com justiça, rendeu-lhe a condecoração com a Ordem Nacional do Mérito Educativo (1972), a indicação como International Man of the Year pelo Centro Biográfico da Universidade de Cambridge (1994) e a presidência e/ou criação de alguns dos primeiros centros brasileiros de orientação e pesquisa na área. Destaco aqui a fundação do Serviço de Seleção e Orientação Profissional (1947), a presidência da Comissão Regional do Fundo Nacional de Ensino Médio (1947), a criação, no INEP (Instituto Nacional de Estudos Pedagógicos), do Centro Brasileiro de Pesquisas Educacionais, com cinco braços regionais (1955), o convênio para o PABAEE (Programa de Assistência Brasileiro-Americano ao Ensino Elementar, 1956), a participação na Comissão Internacional do Currículo Secundário da UNESCO (1957, 1958, 1959), a direção do Centro Regional de Pesquisas João Pinheiro (Belo Horizonte, 1959), a participação no Bureau International d'Education, (Genebra, 1965, 1966, 1967), na Comissão Consultiva Internacional para Educação de Adultos (1968-1972) e no Conselho Nacional de Cultura (1992).

Paradoxalmente, o interesse de Abgar pela qualidade do ensino custou-lhe o cargo de Secretário de Educação em Minas. É que, como antídoto contra os critérios políticos vigentes, ele próprio criara concursos públicos para seleção de candidatos ao magistério mineiro. Coerentemente, insistiu na nomeação de uma professora aprovada em primeiro lugar, em vez da colocada em sétimo lugar, protegida de certos figurões influentes. Diante de sua intolerável pressão, Abgar preferiu demitir-se a trair seus próprios critérios. Até sua aposentadoria em 1969, manteve-se como professor no Departamento de Letras da antiga Faculdade de Filosofia, e, depois, da recém-criada Faculdade de Letras.

O programa de sua disciplina, na verdade inexequível, parecia tudo abranger: em Literatura: ia de Chaucer, o "pai da Literatura Inglesa", a autores pouco estudados no Brasil daqueles tempos, como Virginia Woolf e James Joyce. No tocante à Língua Inglesa, a orientação histórica e morfossintática incluía o estudo da monumental obra de Otto Jespersen, igualmente não muito versada entre nós. Das aulas de Abgar, lembro especialmente sua leitura de Shakespeare. Poeta que era, além de já consagrado pela transcriação, em nossa língua, de Tagore e de poetas ingleses, trazia esse dom para a sala 
de aula. Seria difícil esquecer seu curso sobre Macbeth. Era quase uma vivisseção. Além de analisar a construção poético-dramática, os aspectos históricos, filológicos e psicológicos da peça, e de encontrar equivalentes poéticos para a tradução em português, o professor encenava os papéis. Posso vê-lo ainda, comovido e grave, simulando lavar as mãos, enquanto traduzia a fala de Lady Macbeth tentando apagar as manchas de sangue deixadas pelo regicídio.

No meio de tudo isso, Abgar achava meios e modos de publicar, quase em surdina, e geralmente a suas expensas, sua própria produção poética. Enquanto voava de Brasília, do Rio de Janeiro ou da Europa, para Belo Horizonte, em função de aulas e provas (uma delas como Ministro da Educação), compôs Sofotulafai, que a História da Literatura Brasileira de Carlos Nejar considera "um dos mais belos e vigorosos poemas em nossa língua", e sonetos de muitos matizes, cuja "implícita música", segundo Nejar,"nada devem, em altura e beleza, aos de Drummond ou Jorge de Lima".

Contrariando o folclore sobre os catedráticos tirânicos, Abgar deixava a seus assistentes total liberdade. A disciplina adquiria, assim, o perfil de quem a ministrava. Como o próprio titular, alguns dos assistentes não tinham formação específica em Letras. O brilhante Ian Linklater, cidadão britânico aportado em Belo Horizonte no rebate de sua participação na Segunda Guerra Mundial, era egresso do curso de direito (talvez nunca terminado) de Clare College, da Universidade de Cambridge. Grande conhecedor de Literatura Inglesa, fascinava os estudantes (e as estudantes, tanto que acabou casando com uma) com a vastidão e a variedade de seus conhecimentos, realçados por britânica excentricidade. Linklater tinha visível orgulho de um surrado uniforme escocês, relíquia de seus tempos de jovem capitão. Não perdia a oportunidade de usá-lo em ocasiões de gala, como nos bailes da Cultura Inglesa, então sediada no Edifício Guimarães, na Avenida Afonso Pena. Segundo certos boatos, os moleques se juntavam à entrada do edifício, para vaiar aquele homem louro (na mecha de cabelo que lhe restara, e que ele trespassava sobre a careca), usando saia xadrez. Nos volteios pelo salão, o saiote escocês se enroscava nas saias rodadas de seus pares, conforme a moda dos anos 60. Esse gosto do professor pela dança não se estendia aos esportes. Lembro-me de ouvi-lo queixar-se dos convites que recebia de um colega nosso, o poeta norte-americano Chet Dawson, chegado à Faculdade pelos laços do matrimônio. Chet, que transformou a titular de Literatura Norte-Americana em Alita Sodré Dawson, costumava convidar Linklater para escalar as montanhas de uma ainda jovem $\mathrm{BH}$. O colega inglês não se mostrou muito entusiasmado com o programa que, com o tempo, foi cancelado.

Enquanto docente, Linklater não se preocupava com minúcias como programas e sequência das aulas: seu programa era a aquisição do gosto pelo texto literário e de sua análise. Nisso, foi insuperável, deixando marca em muitos que depois quase abandonaram a Literatura para navegar em sucessivas ondas de abordagens críticas. Dotado de bela voz, esmerava-se na leitura de poemas em voz alta. Num dos primeiros gravadores surgidos em Belo Horizonte, gravou alguns textos - lembro-me de "Fern Hill", de Dylan Thomas - em sessões de leitura, inspiradas, talvez, pelas performances do próprio Thomas, em excursões pelos EUA.

No campo da Língua Inglesa, mourejava outro cidadão britânico, Peter Magnani, também recém-saído da Segunda Grande Guerra. Como Chet Dawson, fixou-se no Brasil 
e encaminhou-se para o magistério por circunstâncias românticas: casou com uma jovem brasileira que conhecera em viagem. A inteligência e aplicação do professor supriram a falta de formação acadêmica. Em plena lua de mel, começou a dar aulas particulares, a partir das 10 da noite. Era o único horário possível para seus primeiros alunos, docentes da Escola de Medicina, trazidos por seu sogro, também médico e professor. A fama das boas aulas levou Peter à Sociedade Brasileira de Cultura Inglesa, e depois, pela mão de Abgar, ao Departamento e à Faculdade de Letras.

À medida que surgiam novas técnicas e materiais, nós, os assistentes, com a liberdade que nos deixava o catedrático, fomos, informal e despreocupadamente, mudando as abordagens e conteúdos programáticos. Separaram-se Língua e Literatura Inglesa, que, com o tempo, desdobraram-se em várias disciplinas. A grande guinada foi, contudo, de natureza política, impulsionada pela Literatura Comparada e pelos Estudos Culturais. A mudança pode ser resumida como a conquista de independência em múltiplas áreas: a superação de paradigmas herdados de instituições estrangeiras, e um posicionamento crítico e interdisciplinar. Ao contrário do que, durante algum tempo, acreditaram colegas de outros departamentos, os apelos de outros falares e tradições literárias não nos transformaram em seres alienados. Pelo contrário. O convívio com a cultura estrangeira exacerbou em nós as angústias das tradições marcadas pela experiência da colonização. Conhecíamos, como poucos, o conflito resumido na fórmula oswaldiana, tupy or not tupy.

Cada vez mais, passamos a considerar o nacional como referência para o ensino de nossas disciplinas. Abandonando os manuais estrangeiros, adotamos práticas pedagógicas apoiadas numa análise contrastiva do inglês e da língua materna. Participamos de projetos nacionais visando à criação de métodos e de material elaborados por professores brasileiros, em função de nossas responsabilidades sociais e das necessidades de nossos alunos. Eu própria elaborei um curso dessa natureza, intitulado Structural English with Audio-Visual Aids, que incluía diversificado material complementar e orientação pedagógica. Na Literatura, enfatizamos leituras "interessantes" (expressão de Silviano Santiago), cada vez mais críticas, calcadas em parâmetros nacionais. Nossos programas passaram a versar não tanto Literatura Inglesa, mas literaturas de expressão inglesa, oriundas das antigas colônias.

Para as conferências inaugurais de nossos congressos, foram sendo convidados especialistas brasileiros, em vez dos enviados por agências culturais inglesas e norteamericanas. Segundo a formulação do livro seminal de Bill Ashcroft, Gareth Griffiths, e Helen Tiffin, The Empire Writes Back (O Império Contra-Escreve, 1989), o Inglês (English), com letra maiúscula, velho instrumento colonizador, tornara-se para nós simplesmente inglês (english), mero veículo de comunicação internacional, marcado pelas identidades de seus usuários, seus variados sotaques, até seu vocabulário e sintaxe.

Essa postura dos professores do chamado Terceiro Mundo certamente contribuiu para mudar também as atitudes nos antigos centros culturais hegemônicos. No Instituto de Educação da Universidade de Londres, o Departamento de Inglês como Língua Estrangeira (Department of English as a Foreign Language, EFL) foi rebatizado como TESOL (Teaching of English to Speakers of Other Languages). A palavra "estrangeiro", com suas possíveis conotações depreciativas, foi substituída pela expressão "falantes de outras línguas", subentendendo o papel ativo e igualitário das trocas culturais. Se é verdade que 
substituímos o olhar estrábico pelo olhar para todos os lados, também o outro hemisfério, ainda que por duvidosas posturas de correção política, busca mudar o olhar que nos devolve.

Assim resumido, o caminho das disciplinas gestadas nas embrionárias Língua e Literatura Inglesa e Literatura Norte-Americana parece ter seguido um traçado definido. $\mathrm{Na}$ verdade, nem sempre, enquanto o percorríamos, o trajeto se mostrou claro, moldado que foi pelas vivências do cotidiano. Assim sendo, nossos cursos abriram caminhos para vôos diversificados. Entre seus primeiros graduados, alguns se encaminharam para Teoria da Literatura e para Literatura Brasileira, como, respectivamente, Eneida Maria de Souza e Marília Rothier Cardoso. Abria-se, assim, um horizonte antes inimaginável, que culminou com a fundação da ABRALIC (Associação Brasileira de Literatura Comparada). Na trilha desses exemplos, estendi meus estudos, antes limitados à produção em língua inglesa; voltei-me para as áreas de Literatura Brasileira e Comparada,com publicações sobre Machado e Sterne, Clarice Lispector, Abgar Renault, Literatura e Artes Plásticas e Literatura e Música. Mais recentemente, Thaïs Flores Nogueira Diniz, outra docente do antigo Departamento de Letras Germânicas, acrescentou novo impulso aos estudos transdisciplinares, com a criação do núcleo de pesquisas intitulado Estudos de Intermidialidade, que inclui docentes de várias unidades da UFMG e de outras universidades. A irradiação dos egressos de nossos cursos manifestou-se também em âmbito internacional, exemplificada por Else Ribeiro Pires, atual responsável pela cadeira de Cultura Brasileira no Queen Anne's College, da Universidade de Londres. Vários outros ex-alunos transformaram-se em professores. Acompanharam com garbo a metamorfose da antiga Literatura Inglesa nas várias literaturas de expressão inglesa. Língua Inglesa, por sua vez, acrescida de disciplinas voltadas para a tradução, transformou-se em campo de pesquisa internacional. Também no campo administrativo mostrou-se fértil nosso grupo.

Dele saiu, por exemplo, Ana Lúcia de Almeida Gazzola, que reestruturou a pósgraduação na UFMG, e veio a ser Reitora da Universidade.

Convenhamos: se, em vez de nostálgica, pareço um tanto orgulhosa, vão ter que me perdoar. 